\title{
DESENVOLVIMENTO DO ESPAÇO RURAL DA MICRORREGIÃO GEOGRÁFICA DE CRUZ ALTA/RS ATRAVÉS DAS IMIGRAÇÕES PORTUGUESA, AÇORIANA E FIXAÇÃO LUSO-BRASILEIRA
}

\author{
Jessica Nene Caetano ${ }^{1}$ \\ Meri Lourdes Bezzi ${ }^{2}$
}

\section{INTRODUÇÃO}

A presente pesquisa visa discutir sobre a contribuição da inserção da matriz cultural lusa no espaço agrário da Microrregião Geográfica de Cruz Alta. Desse modo, este estudo considera a imigração portuguesa e açoriana neste recorte espacial, bem como a fixação luso-brasileira como difusoras das "marcas" culturais lusitanas. Ressalta-se, nesse sentido, que os três referidos grupos sociais, mesmo apresentando diferenças relativas aos seus atributos culturais representativos, foram responsáveis por alicerçar elementos comuns da etnia lusitana, como a língua portuguesa falada e escrita, a religião católica, a crença em santos como Nossa Senhora de Fátima e o Divino Espírito Santo, os quais são lembrados mediante festividades anuais, onde outros códigos culturais lusos são demonstrados, como a gastronomia, as músicas e as danças.

Nesse contexto, esta pesquisa pretende relacionar a inserção da matriz cultural lusa com o desenvolvimento agropecuário da Microrregião Geográfica de Cruz Alta, ressaltando que este recorte regional pertence ao Estado do Rio Grande do Sul e, de acordo com o Instituto Brasileiro de Geografia e Estatística (IBGE), pode ser reconhecido como MRG 011 sendo composto atualmente por 14 unidades territoriais denominadas: Alto Alegre, Boa Vista do Cadeado, Boa Vista do INCRA, Campos Borges, Cruz Alta, Espumoso, Fortaleza dos Valos, Ibirubá, Jacuizinho, Jóia, Quinze de Novembro, Salto do Jacuí, Saldanha Marinho, Santa Bárbara do Sul.

Convém enfatizar que os municípios membros da MRG 011, até o final do século XIX pertenciam ao grande território cruzaltense da época, o qual foi originado da

\footnotetext{
${ }^{1}$ Autora, Graduada em Geografia Licenciatura Plena/UFSM, Mestranda do Programa de Pós-Graduação em Geografia e Geociências - PPGGEO/UFSM. E-mail: sicaetano@yahoo.com.br

2 Orientadora, Professora Doutora do Departamento de Geociências/UFSM. E-mail: meribezzi@yahoo.com.br
} 
freguesia de Rio Pardo, local onde foram instalados muitos açorianos, às margens do Rio Jacuí. Algumas unidades territoriais se emanciparam diretamente do município de Cruz Alta e outras foram inicialmente anexadas a territórios municipais próximos para, posteriormente, obterem autonomia administrativa.

Por conseguinte, esta investigação pretende apontar os subsídios oferecidos pelo grupo cultural luso ao desenvolvimento da atividade agropecuária na MRG de Cruz Alta, destacando os cultivos de erva-mate e trigo, além da criação, transporte e comércio de muares e gado bovino como "heranças" desta matriz cultural.

Evidenciam-se, nessa perspectiva, como objetivos: (a) investigar a contribuição da matriz cultural lusa no espaço rural da Microrregião Geográfica de Cruz Alta; (b) analisar a inserção do grupo cultural luso, representado pela imigração portuguesa e açoriana, além da fixação luso-brasileira na MRG de Cruz Alta, e as produções de trigo, gado, erva-mate e muares como "marcas" da cultura lusitana neste recorte regional e (c) verificar as transformações desta porção espacial promovidas pela chegada de outras correntes imigratórias, em especial, a alemã e italiana e, também, pelo desenvolvimento de novas cadeias produtivas.

Deste modo, esta pesquisa busca constituir-se como uma contribuição para os estudos de Geografia Regional, Geografia Cultural e Geografia Agrária, analisando o papel dos atores que dinamizam e transformam a esfera agropecuária sul-rio-grandense a partir da chegada de diversas correntes imigratórias, enfatizando, a cultura portuguesa como importante grupo social, inserida a partir do luso, luso-brasileiro e açoriano.

\section{FUNDAMENTAÇÃO TEÓRICA}

\subsection{A CONTRIBUIÇÃO DA MATRIZ CULTURAL LUSA NO ESPAÇO RURAL DA MICRORREGIÃO GEOGRÁFICA DE CRUZ ALTA: PORTUGUESES, LUSO-BRASILEIROS E AÇORIANOS}

A inserção da matriz cultural lusa na Microrregião Geográfica de Cruz Alta, assim como no Rio Grande do Sul, ocorreu com um atraso de dois séculos, se comparado ao povoamento português no litoral brasileiro. A existência de gado "xucro" (criado livre) deixado pelos jesuítas no norte do atual Estado atraiu roceiros e tropeiros, 
antigos bandeirantes de origem lusa e luso-brasileira, no período da descoberta do ouro que, devido à necessidade de abastecer essa região mineradora, se dedicaram a invernar gado solto para Sorocaba.

Nessa perspectiva, Bezzi et al (2006) enfatizam que este gado solto, oriundo da Vacaria do Mar e, na região do Planalto, dos rebanhos deixados pelos jesuítas expulsos na Vacaria dos Pinhais atraiu a atenção da Coroa Portuguesa que, ao doar sesmarias para militares de origem portuguesa, evitou a devastação desses animais, promoveu o domínio do território sul rio-grandense, povoou este local ameaçado pela invasão espanhola e passou a desenvolver o mercado interno brasileiro e do Rio Grande do Sul, ao incentivar o abastecimento de carne e animais para carga até as minas do sudeste do Brasil.

Ressalta-se que a doação das sesmarias para os povoadores de origem lusa foi responsável pela consolidação das estâncias na economia local, visto que as mesmas efetivaram a soberania da Coroa Portuguesa sobre este território, já ocupado mediante a realização de invernadas. Relativo às sesmarias, Bezzi $(1985$, p. 18) salienta que "[...] Essa modalidade de ocupação do território, cuja base econômica veio a ser pecuária extensiva, implicava numa grande dispersão da população".

No entanto, a venda de muares "ofuscou" a representatividade da criação de gado na Microrregião Geográfica de Cruz Alta, pois exigia menos cuidados e oferecia maior porcentagem de lucros. Dessa forma, a pecuária, a venda de couro e de carne, que no início da fixação lusa e luso-brasileira na MRG 011 eram as principais fontes de lucratividade nesse território, foram deixadas em segundo plano para que o comércio de muares ganhasse espaço e atenção dos criadores, grande parte, portugueses ou descendentes de lusitanos naturais de São Paulo, Paraná e Minas Gerais. Cavalari (2004, p. 129) acrescenta

[...] o gado tinha pouco ou quase nada de valor, muito embora os campos estivessem relativamente povoados e a carne se constituísse no principal item da população. Somente com o desenvolvimento da indústria das charqueadas na região de Pelotas entre 1860 e 1890 foi que essa atividade refletiu-se no quadro econômico da região, apontando para um bom desenvolvimento e lançando luzes de interesse dos criadores. Depois de revitalizada a criação de gado, os criadores mandavam suas tropas para a tablada pelotense, onde se arrematavam 300 mil bois gordos por ano para abastecer as mais de 20 charqueadas locais. Este charque seguia em navios na direção da Corte ou à Europa, voltando de lá carregados de novidades, que agitavam ainda mais a 
efervescente sociedade daquela cidade, considerada a capital cultural e econômica deste período no Rio Grande do Sul.

Desse modo, com a abertura da Estrada dos Conventos que levava à Vacaria dos Pinhais e a alteração desse caminho para a porção oeste do atual Rio Grande do Sul, conhecido como Caminho Novo da Vacaria, houve maior dinamismo da economia dos territórios que hoje compõem a MRG de Cruz Alta, devido à atividade tropeira.

Destaca-se, também, que a criação de muares promoveu o povoamento do grande território cruzaltense deste período, pois os tropeiros interessados em comercializar estes animais na feira de Sorocaba, cidade localizada no atual Estado de São Paulo, fixavam-se temporariamente nas proximidades onde, hoje, encontra-se a sede do município de Cruz Alta para descansarem, divulgando aos conhecidos, a boa água e pastagens do local, tornando-o referência para a fixação de população, os quais, pertencentes à cultura lusa, inseriram nesse espaço este sistema simbólico representativo.

A atual Microrregião Geográfica de Cruz Alta, aproveitando-se das potencialidades naturais do Planalto sul rio-grandense enfocou em sua esfera produtiva, outro subsídio para a embrionária economia da época - a erva-mate. Desse modo, enfatiza-se que o hábito de beber o chá produzido com esta folha foi enraizado pelos indígenas e incentivado pelos jesuítas para afastar esses nativos do alcoolismo.

Na metade do século XIX, a erva-mate possibilitou o desenvolvimento da área de estudo através da abertura de novos caminhos para que essa produção fosse escoada, juntamente com as criações de bovinos e muares - os três principais elementos da economia dessa porção territorial. Entre os caminhos e picadas abertas por esse imigrante pioneiro, destaca-se a Estrada do Pinhal que, segundo Cavalari (2004, p. 128)

A construção dessa estrada, de cuja obra era inspetor o Guarda-Mor Francisco de Paula e Silva, pai de Firmino de Paula, concretizou-se na década de 1850 e foi determinante para a decadência da Vila de São Martinho, já que o trânsito das Carretas desviou daquele lugar, favorecendo o desenvolvimento da incipiente povoação de Villa Rica, futuro Município de Júlio de Castilhos.

Nesse sentido, evidencia-se, também, a abertura da Estrada dos Conventos e outros caminhos, os quais representavam vantagens para a economia da região, pois não custavam caro à Província e desenvolviam o comércio de erva-mate, enfatizando-se que 
os ervais nas serras e nos pontões de serra localizados na atual MRG de Cruz Alta empregavam muitos moradores dessas localidades, obrigando a preservação desses ervais nativos conforme regulamento estabelecido pelos vereadores do antigo município de Cruz Alta.

Por conseguinte, toda a erva-mate produzida nas localidades que, atualmente, formam a Microrregião Geográfica 011, e até a metade do século XIX faziam parte do município de Cruz Alta, eram direcionadas por meio de carretas vindas de Palmeira das Missões, Nonoai e Soledade até a Fronteira Oriental ou a Itaqui, consolidando esse cultivo como o melhor produto de toda essa área e, também, da região missioneira. A esse respeito Cavalari (2004, p.129) destaca que

Embora se fale da pecuária como base principal da economia gaúcha, notadamente nesta região do Planalto Médio, a extração de erva mate é ponto relevante. [...] A erva-mate, que representava na época cerca da metade do orçamento da Vila, foi o principal item econômico da região seguido de outro que se manteve em atividade desde os primórdios da fundação de Cruz Alta: o comércio de muares.

Considerando a imigração açoriana, Cavalari (2004) reforça que, mediante a utilização da mão de obra de peões e escravos chegados a partir de 1737, o desenvolvimento das grandes propriedades latifundiárias atraiu elevado número de pessoas para o território da atual MRG 011, assim como em todo o Rio Grande do Sul. Bezzi et al (2006, p. 72) assinalam que

Concomitantemente, com as estâncias, promoveu-se a vinda de açorianos para o Rio Grande, instituindo-se, assim, a colonização sistemática do território, a qual se promoveu à fixação do homem a terra. [...] Pode-se dizer, então, que a imigração açoriana para Santa Catarina e Rio Grande do Sul, em meados do século XVII, objetivou garantir a posse das fronteiras, incentivarem a agricultura em pequenas propriedades, uma vez que, a única atividade dominante era a pecuária. Assim, os açorianos foram instalados às margens do rio Jacuí, a fim de garantir o acesso, por via fluvial, a Rio Pardo, que se tornou, o posto mais avançado do domínio português.

Nesse contexto, reforça-se que o território de Rio Pardo, elevado a freguesia em 1776, dominava uma área que, atualmente, abriga a Microrregião Geográfica 011 entre outros municípios. Pode-se considerar desse modo, que a chegada de açorianos à MRG de Cruz Alta remonta este período, sendo o referido grupo social responsável pelo desenvolvimento da produção de trigo no espaço agrário sul rio-grandense da época.

Nesse viés interpretativo, compreende-se que a colonização açoriana efetivou-se de forma distinta da portuguesa em solo rio-grandense e, portanto, do recorte regional 
em questão. A fixação em pequenas propriedades tritícolas, as quais estavam baseadas na mão de obra familiar apresentaram caráter inovador, porém, essas características de fixação e sobrevivência não resistiram à supremacia estancieira e pecuarista. Bezzi et al (2006) ressaltam que as oscilações dos fatores climáticos a que o trigo estava sujeito, assim como, a falta de tendência à lavoura por parte dos colonos açorianos, que julgavam este trabalho como sendo escravo, afastou-os deste cultivo, fazendo-os voltarem-se para a atividade pecuarista, a qual os mesmos poderiam estar protegidos das leis rígidas da época.

Nesse sentido, a influência do latifúndio pecuarista desenvolveu a indústria do charque, sendo esta outra atividade vinculada à imigração açoriana, visto que muitos desses imigrantes dedicaram-se a ela para obterem riqueza e poder políticoadministrativo, assim como os receptores de sesmarias de origem portuguesa.

Frente ao destaque para o estudo da inserção do sistema simbólico luso na MRG 011 a partir das imigrações portuguesa, açoriana e fixação luso-brasileira considerando, assim, as implicações no espaço agropecuário do recorte regional em questão, é necessário apontar que a chegada de correntes imigratórias recentes modificou o cenário cultural e econômico desta porção espacial, em especial, a colonização alemã e italiana.

Evidenciando esta linha de raciocínio, enfoca-se o papel dos imigrantes vindos da Alemanha e Itália para a estruturação de diferentes características do espaço agropecuário da Microrregião Geográfica de Cruz Alta. Grandes propriedades de terras pertencentes aos povoadores de origem lusa foram demarcadas e divididas para estes colonos, destacando, entre as mais expressivas, a colônia de Santa Clara do Ingaí, atual município de Quinze de Novembro. A população que reside neste local, hoje, apresenta origem alemã e manifesta códigos culturais representativos, entre eles, a oralidade e a escrita em alemão, os Kerbs como festividades anuais, a religião Luterana, entre outros atributos.

É possível compreender, também que estes imigrantes realizaram com sucesso nas colônias integrantes do território da atual MRG de Cruz Alta, uma agricultura de subsistência, alicerçada na mão de obra familiar, voltada para consumo interno e venda direcionada aos estabelecimentos de áreas vizinhas. Diferentes dos imigrantes açorianos 
os colonos alemães e italianos integraram-se facilmente com as atividades agrícolas, elaborando suas técnicas e criando alternativas para a superação dos fenômenos climáticos imprevisíveis.

Através das questões abordadas, verifica-se que a matriz cultural lusa desenvolveu consideravelmente o espaço agropecuário da Microrregião Geográfica de Cruz Alta, atribuindo como elementos representativos desta cultura a criação de gado, o cultivo de erva-mate, o transporte e criação de muares e o plantio do trigo.

\subsection{TRANSFORMAÇÕES DO ESPAÇO RURAL DA MICRORREGIÃO GEOGRÁFICA DE CRUZ ALTA: REFLEXOS DA INSERÇÃO DE NOVOS GRUPOS CULTURAIS E CADEIAS PRODUTIVAS}

A Microrregião Geográfica de Cruz Alta, de acordo com Bezzi et al (2006) encontra-se na Região Geoeconômica 7, ou seja, consolida a esfera econômica de seu espaço rural através da produção de soja, trigo, milho, bovinos e aves. Nessa perspectiva, analisa-se que, dentre estas, o desenvolvimento do binômio trigo-soja em médias e grandes propriedades deste recorte regional promoveu consideráveis transformações na estruturação econômica desta porção espacial. De acordo com Bezzi et al (2006, p. 215) " [...] as culturas da soja, trigo e milho constituem a matriz tradicional desta região geoeconômica. Salienta-se que a sua produção agrícola antes da inserção da soja, baseava-se em culturas de subsistência e na fruticultura".

Nesse contexto, afirma-se que o cultivo de soja e trigo na MRG 011 está vinculado ao processo de modernização agrícola iniciada na década de 1970. Antes, estas lavouras encontravam-se em pequenas propriedades e não eram direcionadas ao comércio de exportação. Ressalta-se, novamente, a contribuição do trigo para a consolidação da pequena propriedade no Rio Grande do Sul a partir da chegada dos açorianos que, por falta de afinidade com o trabalho agrícola e pelo ataque da praga "ferrugem" neste cultivo, desistiram de investir na produção tritícola e passaram a desenvolver, assim como os imigrantes portugueses e os povoadores luso-brasileiros, a pecuária extensiva e o trabalho nas charqueadas.

Portanto, afirma-se que o trigo foi desenvolvido efetivamente no espaço rural da Microrregião Geográfica de Cruz Alta com a imigração alemã e italiana e, a partir de 
1954, surgiram às primeiras lavouras mecanizadas nesta porção espacial, assim como em todo o Rio Grande do Sul. A MRG 011 possui em Cruz Alta a Fundação Centro de Experimentação e Pesquisa Fecotrigo (FUNDACEP/FECOTRIGO), referência em pesquisas voltadas ao estudo da triticultura e, também, das produções de leite, soja, forrageiras, solos, doenças e pragas.

No que diz respeito a produção de trigo, a tabela 1 demonstra a representatividade deste cultivo de 2004 a 2009 na MRG 011.

\section{Tabela 1 - Produção de trigo na Microrregião Geográfica de Cruz Alta/RS em grãos- 2005 a 2009}

\begin{tabular}{|ccccc|}
\hline 2005 & 2006 & 2007 & 2008 & 2009 \\
\hline 145134 & 54202 & 192078 & 261279 & 185154 \\
\hline
\end{tabular}

Fonte: IBGE, 2011

Org: CAETANO, Jessica Nene, 2011

Pode-se considerar que o trigo e a soja, mediante a produção em pequenas, médias e grandes propriedades foram os responsáveis pelo considerável impulso industrial na Microrregião Geográfica de Cruz Alta, pois este recorte espacial apresentou os requisitos básicos para a ascensão da lavoura empresarial, como abundante força de trabalho, expressivas extensões de terras, solo, distribuição de chuvas e temperatura apropriadas para o desenvolvimento destas culturas. Bezzi et al (2006, p. 224) salientam que

[...] a partir da década de 70, o pacote tecnológico que o Governo passou a incentivar via políticas públicas a cadeia produtiva da soja. Os financiamentos visavam propiciar ao agricultor subsídios principalmente para a modernização da agricultura, visando incentivar a produção do binômio trigo-soja, como forma de incluir esta região no processo produtivo capitalista, baseado na lavoura empresarial voltado, principalmente, para o mercado externo, no caso da soja e interno no caso do trigo.

Estas características chamaram a atenção de empresas de fertilizantes, insumos químicos, maquinário agrícolas e metalúrgicas de confecção de sistemas de armazenamento de grãos, como a Kepler Weber, indústria criada e localizada no município de Panambi, o qual não integra a MRG 011, mas desempenha importante papel no agronegócio deste recorte regional ao produzir silos, secadores, entre outros equipamentos. Nessa linha de raciocínio, recorre-se mais uma vez a Bezzi et al (2006, p. 221) quando a autora enfoca que 
Desta forma, as lavouras temporárias desenvolveram-se atendendo ao mercado interno e externo, propiciando divisa ao país e possuindo uma política de incentivos agrícolas que facilitou e acelerou o processo de adoção de técnicas modernas na agricultura gaúcha. Isto se constituiu em um importante motivo que relegou a lavoura permanente a um segundo plano do Estado.

Desse modo, quando se trata da diminuição de importância econômica das lavouras temporárias, pode-se evidenciar a queda de produtividade da erva-mate nesse recorte espacial, principalmente, se comparar o ano de 1992 e 2009 (Tabela 2). Esta queda não foi gradativa, porém, os sinais de desprestígio deste cultivo nesta esfera econômica da MRG de Cruz Alta são visíveis a partir dos números apresentados.

\section{Tabela 2 - Produção de erva-mate na Microrregião Geográfica de Cruz Alta/RS em toneladas - 1992 a 2009}

\begin{tabular}{|cccc|}
\hline Ano & Prod/Ton & Ano & Prod/Ton \\
\hline 1992 & 1153 & 2001 & 988 \\
1993 & 1242 & 2002 & 990 \\
1994 & 1499 & 2003 & 1046 \\
1995 & 1387 & 2004 & 998 \\
1996 & 809 & 2005 & 998 \\
1997 & 1129 & 2006 & 702 \\
1998 & 1097 & 2007 & 686 \\
1999 & 1107 & 2008 & 877 \\
2000 & 1207 & 2009 & 880 \\
\hline
\end{tabular}

Fonte: FEE, 2011

Org: CAETANO, Jessica Nene, 2011

Com a modernização da agricultura, a lavoura empresarial da soja passou a representar importância na economia deste recorte espacial a partir da etapa que se iniciou no ano de 1968 até a década de 1980 (FEE, 1978). Os dados do IBGE (2011) expressam que na primeira metade do início do século XXI a lavoura empresarial da soja cresceu constantemente, com exceção do ano de 2005, período marcado pela escassez de chuva em todo o Rio Grande do Sul.

Após este período de expansão, a Região Geoeconômica a qual a MRG 011 faz parte, passou por uma fase de retração devido à disputa com a produção internacional mais barata por utilizar tecnologia avançada. A alternativa encontrada para este problema, foi o plantio da soja transgênica, um tipo de semente mau "visto" pelos 
consumidores da Europa que, de acordo com Bezzi et al (2006, p. 226) exigiram dos agricultores brasileiros

[...] a plantação de metade da safra com semente convencional e a outra metade com semente transgênica garantindo, assim, a comercialização da produção e o retorno financeiro investido nessa tecnologia. [...] Portanto, o plantio de soja transgênica caracteriza atualmente esta região produtora e configura um novo arranjo produtivo viabilizando dinamizar economicamente este recorte espacial, através da expansão desta cultura aliada ao trigo e ao milho.

Atualmente, a sojicultura representa o cultivo de maior expressão na MRG 011, mantendo-se como escolha de grande parte dos agricultores deste recorte espacial (Tabela 3).

Tabela 3 - Produção de soja em grãos na Microrregião Geográfica de Cruz Alta/RS em toneladas - 2004 a 2009

\begin{tabular}{|ccccccc|}
\hline Ano & 2004 & 2005 & 2006 & 2007 & 2008 & 2009 \\
\hline Prod/Ton & 784270 & 338528 & 1010378 & 1138118 & 1025228 & 1086815 \\
\hline
\end{tabular}

Fonte: IBGE, 2011

Org: CAETANO, Jessica Nene, 2011

A modernização da agricultura levou à decadência da agropecuária colonial, pois, de acordo com Bezzi et al (2006) a introdução maciça da soja em detrimento de outros produtos ou pela expulsão dos seus antigos proprietários via escassez jurídica do fator terra, uma vez que a fronteira agrícola encontra-se praticamente fechada a partir de 1950 no estado gaúcho.

Assim, as áreas de pecuária extensiva, representante da inserção da matriz cultural lusa na MRG 011 “cedeu espaço” para as Novas Colônias alemãs e italianas. Este recorte espacial, de 1992 a 2009 produziu considerável número de cabeças de gado (Tabela 4), no entanto, os mesmos não são destinados, apenas, para o corte, mas também, para a produção de leite, visto que o município de Cruz Alta possui uma cooperativa de beneficiamento de leite, denominada Cooperativa Central Gaúcha de Leite Ltda (CCGL). Bezzi et al (2006, p. 228) salienta

Os bovinos concentram-se na porção centro-sul da região econômica 7 , principalmente, nos maiores municípios e que, anteriormente, a inserção da agricultura já desenvolviam a pecuária tradicional e representam a continuação desta atividade econômica, numa área onde, atualmente, a atividade agrícola é bastante expressiva. Tal situação demonstra a 
coexistência da atividade agropecuarista nesta região e, também, a inserção de novas dinâmicas para este recorte espacial, principalmente com a fruticultura.

\title{
Tabela 4- Produção de cabeças de gado na Microrregião Geográfica
} De Cruz Alta/RS - 1992 a 2009

\begin{tabular}{|cccc|}
\hline Ano & $\boldsymbol{n}^{\boldsymbol{o}}$ cabeça & Ano & $\boldsymbol{n}^{\boldsymbol{o}}$ cabeças \\
\hline 1992 & 297663 & 2001 & 252336 \\
1993 & 294451 & 2002 & 217429 \\
1994 & 297273 & 2003 & 200734 \\
1995 & 298974 & 2004 & 188896 \\
1996 & 297399 & 2005 & 190334 \\
1997 & 301554 & 2006 & 197333 \\
1998 & 280940 & 2007 & 199528 \\
1999 & 280893 & 2008 & 216090 \\
2000 & 257199 & 2009 & 223386 \\
\hline
\end{tabular}

Resgata-se, nessa perspectiva, FEE (1978 apud Bezzi et al 2006, p. 225) quando é enfocado que

\begin{abstract}
A pecuária tradicional começou a perder substância e o fenômeno se tornou transparente quando terrenos férteis ocupados por esse segmento começaram a aparecer no mercado de terras para alugar. Para o segmento pecuarista como um todo, o importante é a manutenção de certo nível de renda que pode ser alcançado, tanto através do lucro mercantil da pecuária, sem alteração da sua estrutura técnica de produção, quanto através da renda da terra, cedendo seu espaço econômico para o segmento da agricultura capitalista.
\end{abstract}

Outra importante criação, a qual foi responsável pelo desenvolvimento da imigração lusa e açoriana na MRG 011 e, atualmente, não manifesta a atenção dos pecuaristas, é a produção de muares. Os números abaixo apresentados, obtidos mediante verificação dos dados da Fundação de Economia e Estatística (FEE) demonstram que do ano de 1992 ao ano de 2009 (Tabela 5), houve diminuição significativa de cabeças de muares na MRG de Cruz Alta, porém, este decréscimo não se mostra gradativo ano após ano. 
Tabela 5- Produção de cabeças de muares na Microrregião Geográfica de Cruz Alta/RS - 1992 a 2009

\begin{tabular}{|cccc|}
\hline Ano & $\boldsymbol{n}^{\boldsymbol{o}}$ cabeça & Ano & $\boldsymbol{n}^{\boldsymbol{o}}$ cabeças \\
\hline 1992 & 156 & 2001 & 84 \\
1993 & 143 & 2002 & 84 \\
1994 & 157 & 2003 & 76 \\
1995 & 162 & 2004 & 74 \\
1996 & 75 & 2005 & 68 \\
1997 & 57 & 2006 & 69 \\
1998 & 84 & 2007 & 67 \\
1999 & 81 & 2008 & 67 \\
2000 & 83 & 2009 & 75 \\
\hline Fonte: FEE, 2011 & \\
Org: CAETANO, Jessica Nene, 2011
\end{tabular}

Evidenciando o papel transformador das correntes imigratórias recentes, destacam-se a colonização alemã e italiana na MRG 011, enfocando a relação dessas etnias com a inserção efetiva da pequena propriedade rural, alicerçada na policultura agrícola, voltada para a subsistência, bem como para a criação de animais utilizados também para subsistência.

A colonização alemã, iniciada a partir do ano de 1824 no Rio Grande do Sul, ocorreu posteriormente na MRG 011, com imigrantes vindos do Vale do Rio dos Sinos, entre outras localidades. Essas famílias se fixaram em pequenas colônias próximas ao Rio Jacuí, como a de Santa Clara do Ingaí, atual município de Quinze de Novembro. Outras unidades territoriais, como Saldanha Marinho, Santa Bárbara do Sul e Ibirubá também se destacam pelo elevado número de imigrantes alemães.

A imigração alemã na Microrregião Geográfica de Cruz Alta foi responsável pelo plantio do milho, feijão, batata, mandioca e trigo, além da criação de suínos para a fabricação de toucinho e banha. Esses cultivos, realizados em pequenas propriedades, serviam para a subsistência da família, com a comercialização dos excedentes em pequenos estabelecimentos.

A imigração italiana, ocorrida após o ano de 1875 na MRG 011, "abrigou" famílias vindas de Val de Serra, São Martinho e da Quarta Colônia, as quais inseriram no espaço rural deste recorte regional características semelhantes às apresentadas pela fixação alemã, sendo os municípios de Espumoso, Alto Alegre, Fortaleza dos Valos e 
Jóia entre outros, os mais representativos quanto à presença desta etnia. Os cultivos produzidos por esses colonos eram os mesmos dos alemães, porém, devido a sua chegada posterior, a imigração italiana na MRG 011 se viu favorecida pelo comércio implantado pelos alemães.

Pode-se dizer que, tanto a colonização alemã, quanto a italiana, evoluiu economicamente de forma considerável na MRG de Cruz Alta. Iniciando suas produções em pequenas propriedades rurais, estas etnias, ao comercializarem seus excedentes, adquiriram através da compra, maiores extensões de terras e, atualmente, seguem a tendência produtiva de todo o Rio Grande do Sul e da Região Geoeconômica a qual a Microrregião Geográfica de Cruz Alta faz parte: o plantio do binômio trigosoja, integrando-o com o milho e a criação de gado.

\section{METODOLOGIA}

Esta pesquisa foi estruturada metodologicamente a partir da revisão em referências bibliográficas, as quais subsidiaram teoricamente a presente investigação. Posteriormente, recorreu-se a fontes de dados censitários disponibilizados via web, destacando o site do Instituto Brasileiro de Geografia e Estatística (IBGE) e da Fundação de Economia e Estatística (FEE). Outro importante subsídio para este estudo foi a análise dos dados e interpretações do (PROADE), elaborado pelos pesquisadores do Núcleo de Estudos Regionais e Agrários da Universidade Federal de Santa Maria (NERA/UFSM/2006), o qual é coordenado pela Professora Doutora Meri Lourdes Bezzi.

Por fim, fez-se a vinculação dos dados e análises obtidas através das referências apontadas com a Microrregião Geográfica de Cruz Alta, visando apresentar um breve diagnóstico sobre a relação entre a inserção de diferentes etnias, em especial a matriz cultural lusa neste recorte regional com as transformações de seu espaço rural no que se refere às cadeias produtivas apresentadas. 


\section{RESULTADOS}

Como resultados, esta pesquisa aponta que, entre as contribuições oferecidas pela matriz cultural lusa no espaço rural da Microrregião Geográfica de Cruz Alta podese destacar:

A criação de gado - Herança das doações de sesmarias pela Coroa Portuguesa aos militares de origem lusa para domínio e defesa do território. A criação extensiva de gado no espaço da atual MRG de Cruz Alta representou a atividade pioneira neste recorte regional, evidenciando-se que a presença de boas pastagens e água para estes animais favoreceu esta atividade, a qual fornecia couro e carne para os primeiros povoadores lusos e luso-brasileiros.

A criação de muares - No território da Microrregião Geográfica de Cruz Alta, esta atividade representou maior importância do que a criação de gado, visto que os cuidados exigidos pela criação de muares eram menores, tornando-a mais barata. Enfatiza-se, também, que este tipo de criação favoreceu a atividade tropeira, a qual se estruturou no transporte de mulas até a Feira de Sorocaba, em São Paulo.

O grande território cruzaltense, por fazer parte do caminho das tropas, atraiu povoadores vindos de outras localidades do Brasil, entre eles, muitos portugueses e luso-brasileiros, os quais possibilitaram a formação e desenvolvimento do povoado, da vila e, posteriormente, do município que, a partir do final do século XIX diminuiu sua extensão devido, entre outros motivos, a emancipação de seus distritos.

A produção de erva-mate - Herança da cultura indígena, reforçada pela presença jesuítica na região das Missões, a qual a MRG 011 encontra-se próxima. Devido à abundância desses ervais no Planalto sul rio-grandense, onde a Microrregião Geográfica de Cruz Alta está localizada, o povoador luso/luso-brasileiro consolidou este cultivo, não apenas, como meio para obtenção de lucro, mas como impulsionador na criação de novos caminhos os quais dinamizaram o transporte desta erva para as demais localidades do atual Rio Grande do Sul.

O cultivo do trigo - Consolidou-se, através da imigração açoriana, como a primeira tentativa de implantação da pequena propriedade nas terras sul rio-grandenses. Pode-se considerar que foi através da criação da Freguesia de Rio Pardo, a qual o extenso território cruzaltense pertencia que esses colonos se fixaram onde, atualmente, encontra-se a MRG 011. Desse modo, enfatizase que os açorianos não permaneceram dedicados à triticultura, pois as pragas, a falta de 
habilidade e as duras legislações deste período tornavam este cultivo pouco rentável frente às possibilidades oferecidas pela pecuária e a indústria das charqueadas.

Nessa linha de raciocínio, a presente investigação analisa, também, que atualmente, os referidos cultivos e criações, considerados como "marcas" da cultura lusitana, apresentam o seguinte desempenho econômico no espaço rural da MRG 011:

A criação de gado - Atualmente, esta atividade apresenta-se favorável ao pecuarista da MRG 011. De acordo com os dados do IBGE (2009) o município de Jóia é o mais representativo, com 47. 500 cabeças, sendo Alto Alegre e Saldanha Marinho os menos significativos com, respectivamente, 4.250 e 5.359 cabeças de gado (Gráfico 1).

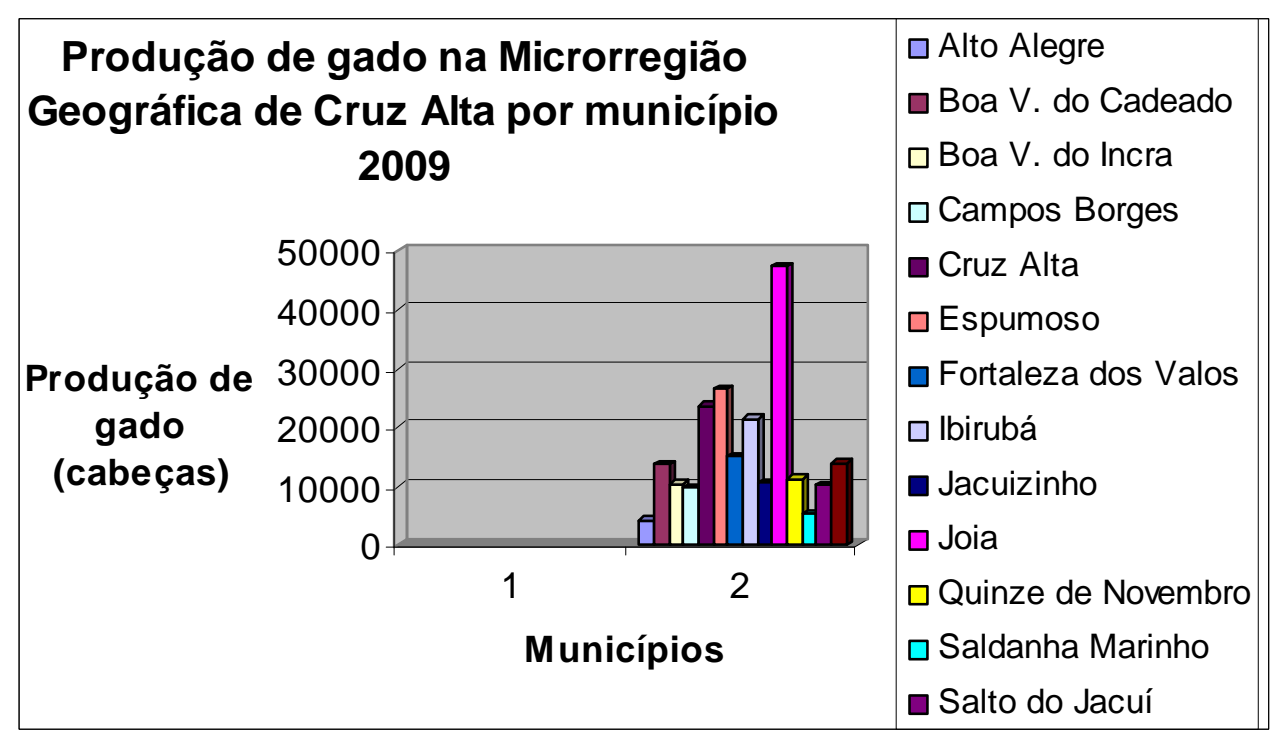

Fonte: IBGE, 2009

Org: CAETANO, Jessica Nene, 2011.

Considerando, também, os dados da FEE (2009), a Microrregião Geográfica de Cruz Alta apresenta cerca de 223. 386 cabeças de gado, sendo, portanto, uma atividade representativa para este recorte espacial,que remonta o passado da imigração portuguesa, açoriana e da fixação luso-brasileira.

A criação de muares - Hoje, esta criação não expressa ganho econômico para a Microrregião Geográfica de Cruz Alta e, nesse sentido, a presença destes animais no recorte espacial em questão expressa a utilidade dos mesmos para o transporte e as atividades secundárias no campo. O gráfico 2 demonstra a perda de representatividade desta criação nas 14 unidades territoriais que integram a MRG 011. 


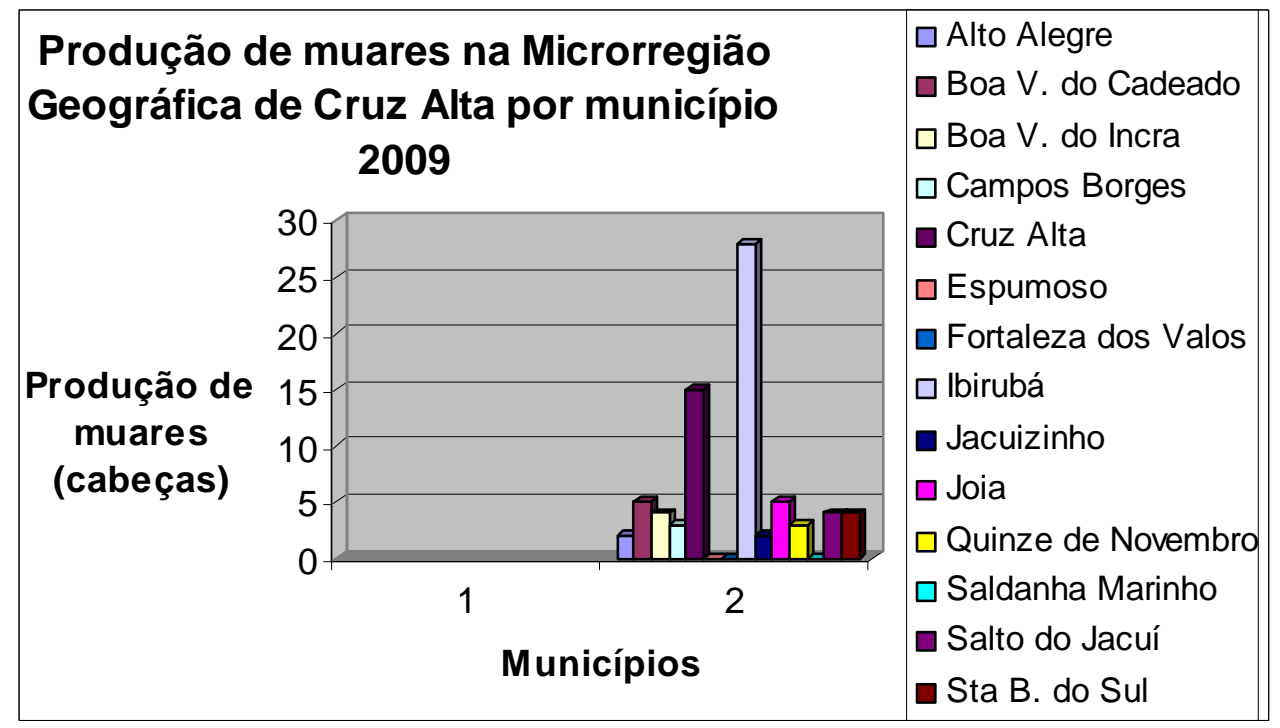

Fonte: IBGE, 2009

Org: CAETANO, Jessica Nene, 2011.

A produção de erva-mate - As 14 unidades territoriais que compõem a Microrregião Geográfica de Cruz Alta, sendo favorecidas pelas potencialidades naturais, as quais possibilitam abundância da produção de erva-mate, agregam este cultivo em suas economias. No entanto, esta produção frente às cadeias produtivas da soja, trigo e milho, não apresenta competitividade, consolidando-se como uma complementação para a agricultura empresarial deste recorte espacial. O gráfico 3 comprova a referida afirmação.

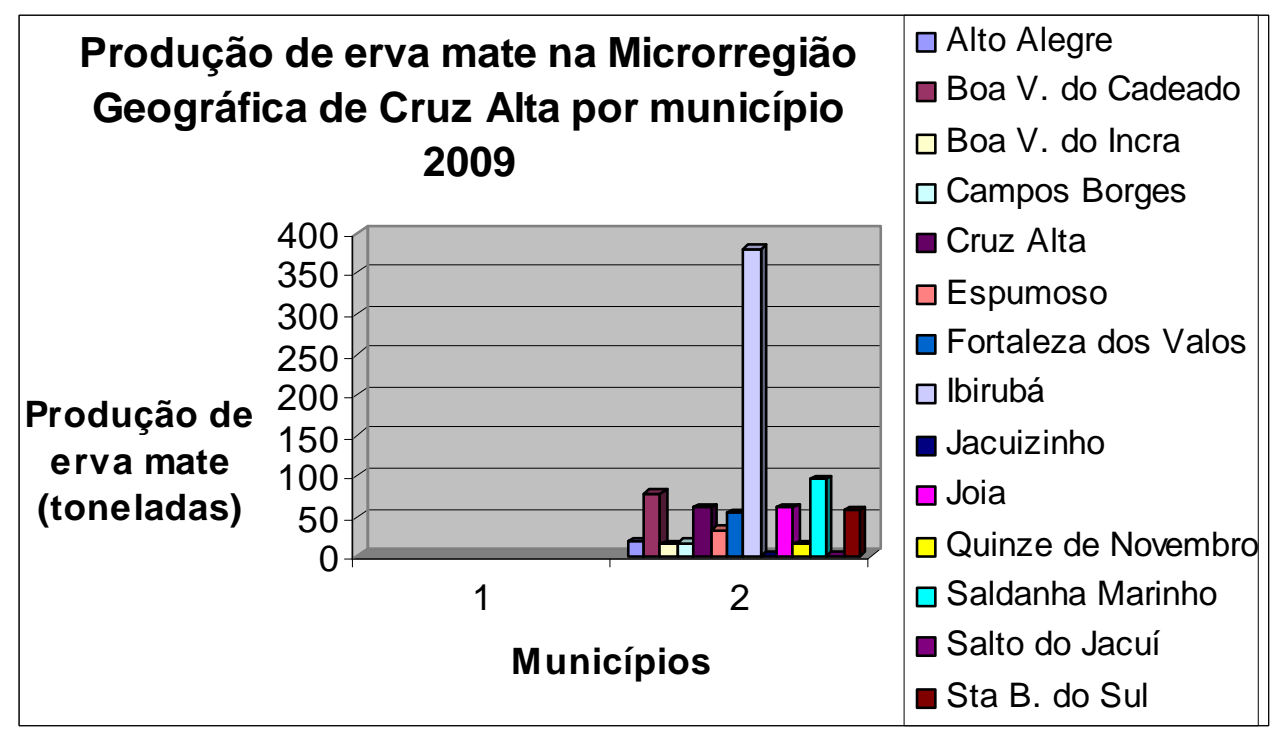

Fonte: IBGE, 2009

Org: CAETANO, Jessica Nene, 2011. 
Nesse contexto, o recorte espacial em questão apresentou um ganho de 303 mil reais em 2009 (IBGE, 2009), sendo um valor inexpressivo, comparado à representatividade econômica da soja, milho e trigo na MRG 011.

O cultivo do trigo - Juntamente com a soja, representa a expressão da economia agrícola da MRG de Cruz Alta. De acordo com a FEE, em 2010 este recorte regional apresentou uma produtividade de 1974800 toneladas e, em 2011, esses números aumentaram para 2017900 toneladas. Conforme os dados do IBGE (2009) os municípios que compõem a MRG 011 produziram os seguintes valores (Gráfico 4):

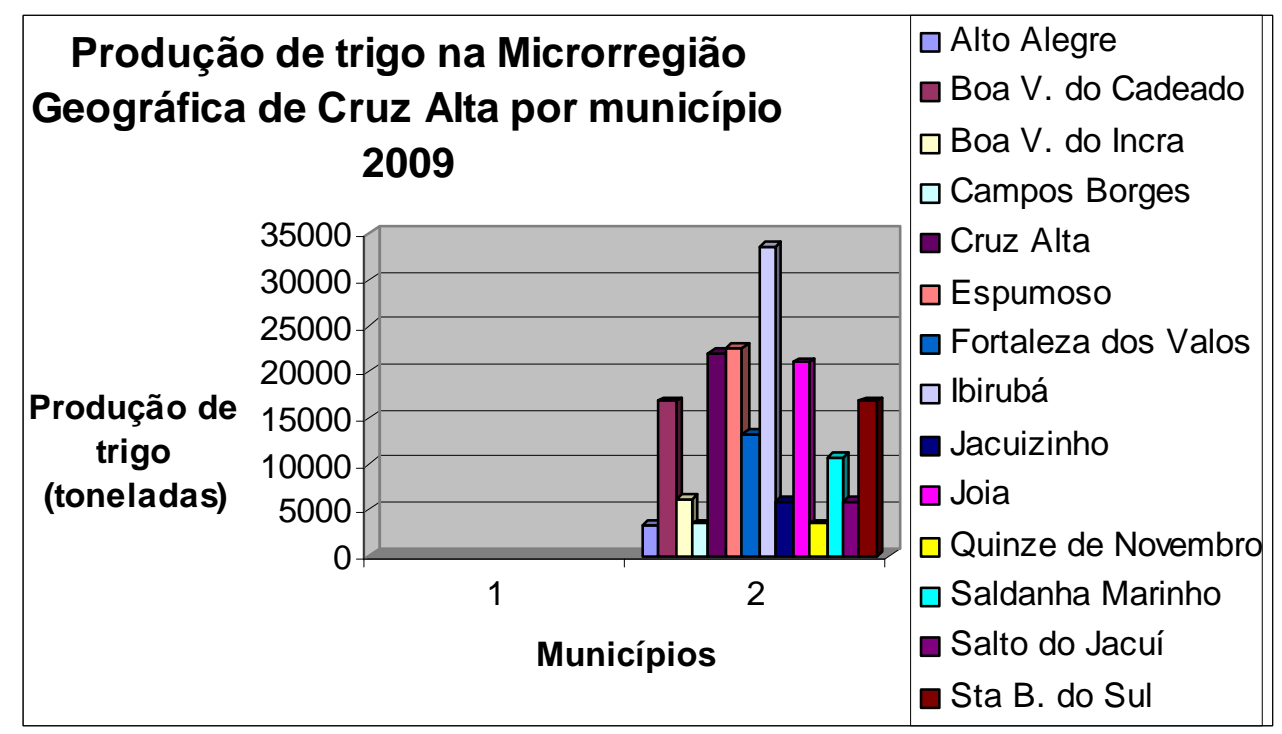

Fonte: IBGE, 2009

Org: CAETANO, Jessica Nene, 2011

Convém enfatizar que MRG de Cruz Alta obteve, em 2009, um ganho R\$ 71.212 com esta produção.

Desse modo, este estudo afirma como "agentes" transformadores do espaço rural desta porção espacial:

As correntes imigratórias alemã e italiana - Estes imigrantes, como já enfatizado, foram responsáveis pela consolidação da agricultura de subsistência na Microrregião Geográfica de Cruz Alta. Destacando os principais cultivos desenvolvidos por esses imigrantes, citam-se o feijão, a mandioca, o milho e a batata nas 14 unidades territoriais, os quais permanecem como "marcas" da inserção destas etnias. Em 2010 e 2011, conforme dados da FEE anunciados no gráfico 5, houve a seguinte produtividade: 


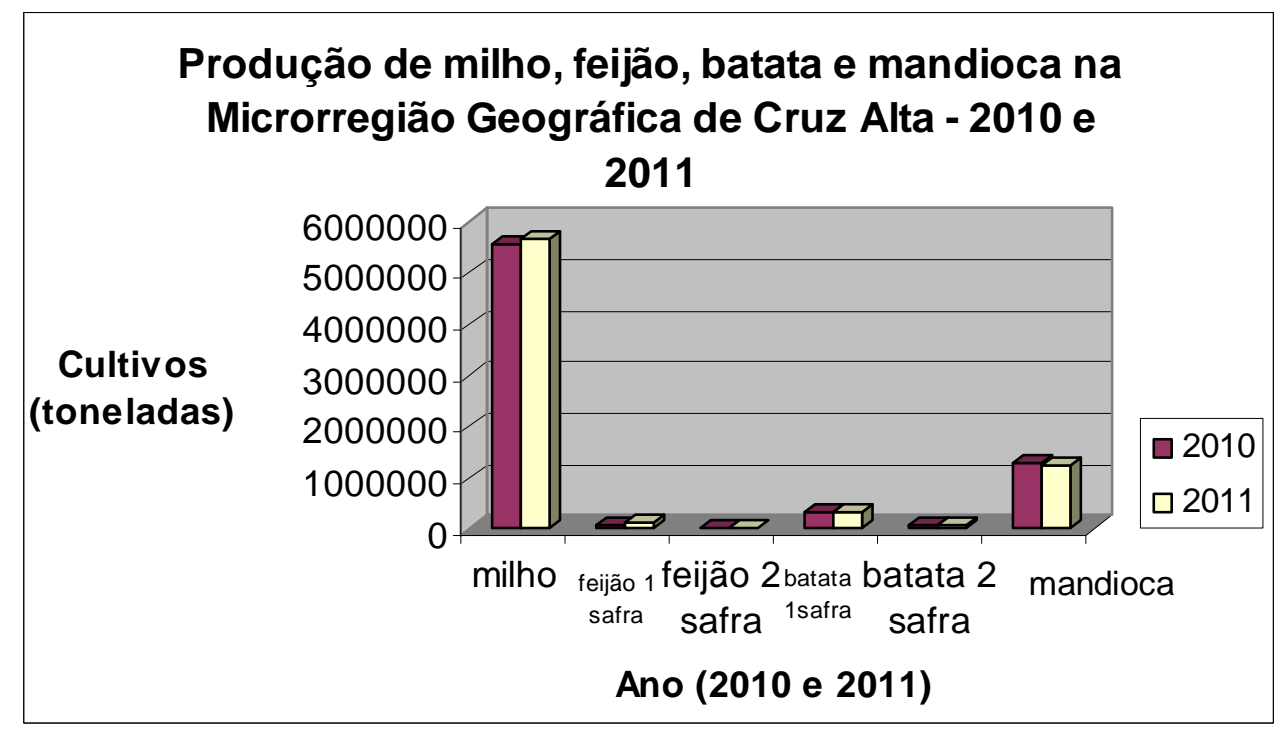

Fonte: FEE, 2011

Org: CAETANO, Jessica Nene, 2011

O binômio trigo-soja - A integração desses dois cultivos representa a lavoura empresarial a qual toda a Microrregião Geográfica de Cruz Alta encontra-se atrelada. Evidenciando a necessidade de interpretar a representatividade atual da soja, visto que já foi apresentado brevemente a expressividade do trigo nesse recorte espacial, destaca-se, de acordo com a FEE, que em 2010, a sojicultura representou cerca de 10218800 toneladas colhidas na MRG de Cruz Alta e, em 2011, esses números foram elevados para 11621300 toneladas. Nesse sentido, o gráfico 6 apresenta os dados do IBGE sobre a produção de soja nas 14 unidades territoriais da MRG 011 em 2009.

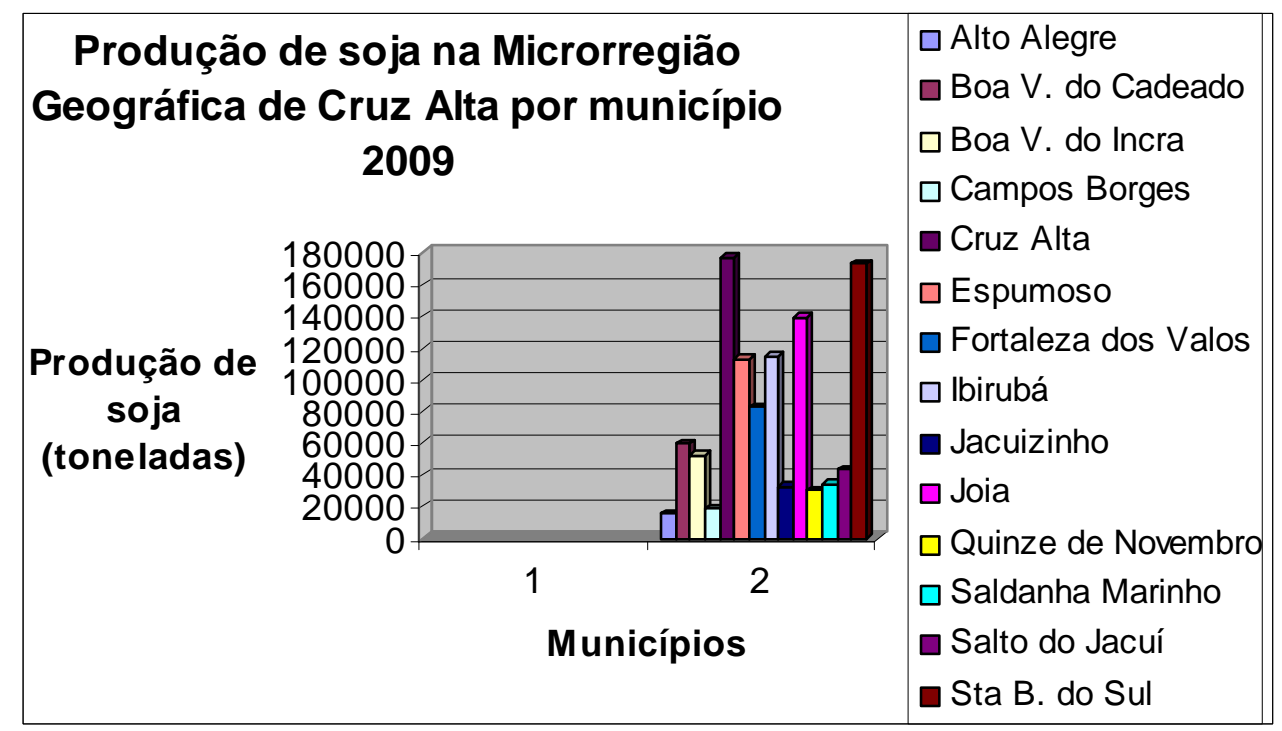

Fonte: IBGE, 2009

Org: CAETANO, Jessica Nene, 2011 
Por conseguinte, os dados apresentados demonstram que estatisticamente, a Microrregião Geográfica de Cruz Alta apresenta como características de produtividade agropecuária, os atributos apresentados por Bezzi et al (2006), os quais revelam a expressividade econômica do binômio trigo-soja, atrelado à produção de milho e à pecuária.

Desse modo, resistem como heranças da matriz cultural lusa, a pecuária bovina e, em menor, representatividade, a produção de erva mate. Pode-se considerar quase inexpressivo, o legado luso da criação de muares e a produção do trigo em pequenas propriedades, um cultivo iniciado pelos açorianos e efetivado pelos imigrantes alemães e italianos. Ressalta-se, nesse sentido, que a produção de trigo atualmente está ligada à lavoura empresarial.

\section{CONSIDERAÇÕES}

A realização do presente estudo visou atrelar a pesquisa sobre desenvolvimento do espaço rural da Microrregião Geográfica de Cruz Alta e suas principais cadeias produtivas, com a inserção da matriz cultural lusa compreendida nas imigrações portuguesa e açoriana além da fixação luso-brasileira. Nesse sentido, pode-se verificar que existiu essa relação e que a representatividade das criações de gado e muares somados aos cultivos de erva mate e trigo como elementos representativos da cultura portuguesa foram sendo modificados com a chegada de outras correntes imigratórias, em especial, a alemã e italiana.

Atualmente, esta relação entre grupos culturais, cultivos agrícolas e criações de animais não se mostram tão estreitas, devido, ao avanço de uma política econômica global, a qual se centra na lavoura empresarial voltada para a exportação. A vinculação entre trigo-soja e milho expressa esta tendência na produtividade do espaço rural que, ligada à pecuária intensiva, não somente de corte, mas de produção de leite, "anunciam" que a MRG 011 está consolidada às tendências econômicas atuais.

Por conseguinte, este estudo pretende gerar novos questionamentos e discussões, servindo, também, como um "instrumento" difusor das características culturais e econômicas do espaço rural da Microrregião Geográfica de Cruz Alta. 


\section{REFERÊNCIAS}

BEZZI, et al. RS: Uma proposta de regionalização considerando os aspectos geoeconômicos. Relatório Técnico Científico. (PROADE 2 - FAPERGS). Universidade Federal de Santa Maria, 2006.

São Borja - Transformações no Espaço Agropecuário: O processo de Despecuarização. 1985. 222 f. Dissertação (Mestrado em Organização do Espaço). Universidade Estadual Paulista. Rio Claro. 1985.

CAVAlARI, Rossano Viero. A Gênese da Cruz Alta, Cruz Alta: Ed. da UNICRUZ, 2004, 245 p.

COOPERATIVA CENTRAL GAÚCHA DE LEITE LTDA - CCGL. A CCGL. Cruz Alta, 2011. Disponível em: <http://www.ccgl.com.br> Acesso em: 30/08/2011.

FUNDACEP FECOTRIGO. Contato. Cruz Alta, 2011. Disponível em <http://www.fundacep.com.br/contato.php> Acesso em: 30/08/2011.

FUNDAÇÃO DE ECONOMIA E ESTATÍSTICA - FEE. FEE Dados. Porto Alegre, 2011. Disponível em: <http://www.ccgl.com.br/feedados> Acesso em: 20/07/2011.

INSTITUTO BRASILEIRO DE GEOGRAFIA E ESTATÍSTICA - IBGE. IBGE Cidades. Rio de Janeiro, 2011. Disponível em: <http://www.ibge.gov.br/cidadesat> Acesso em: 20/07/2011.

KEPLER WEBER. A Indústria. Panambi, 2011. Disponível em: <http://www.kepler.com.br/view> Acesso em: 30/08/2011. 